\title{
IMAGEM PÚBLICA E DIVULGAÇÃO DA QUÍMICA: DESAFIOS E OPORTUNIDADES
}

Leila Cardoso Teruya e Guilherme Andrade Marson*

Departamento de Química Fundamental, Instituto de Química, Universidade de São Paulo, Av. Prof. Lineu Prestes, 748, 05508-000

São Paulo - SP, Brasil

Claudia Moraes de Rezende

Instituto de Química, Universidade Federal do Rio de Janeiro, Av. Athos da Silveira Ramos, 149, B1. A, 21941-909 Rio de Janeiro - RJ, Brasil Mario Henrique Viana

AllComm Partners Comunicação Estratégica, Rua Alvarenga, 806, 05509-001 São Paulo - SP, Brasil

Recebido em 11/7/13; aceito em 4/9/13; publicado na web em 18/9/13

\begin{abstract}
PUBLIC IMAGE AND DIVULGATION OF CHEMISTRY: CHALLENGES AND OPPORTUNITIES. Chemical knowledge plays a central role in the economical and social development of a nation. Chemistry is considered a key science, which provides the means and meanings that fuel the advancement of other fields of knowledge. However, the public image of chemistry is often associated with negative facts and misconceptions. This paper addresses and discusses the public image of chemistry with two case studies: the public image of chemistry depicted in two major Brazilian newspapers and the Brazilian project for the International Year of Chemistry (IYC). Analysis of the newspaper data strongly suggests that the public image of chemistry is related to both the way news is written and the ability of the reader to identify the chemical knowledge actually present in the text. Analysis of IYC related data in the second case study depicted an optimistic panorama for the divulgation of chemistry at both national and local levels. A model for broad and effective initiatives for dissemination of chemistry is discussed. The need to keep science divulgation as the top agenda of the scientific community is also highlighted.
\end{abstract}

Keywords: public awareness of science; popularization of science; public image of Chemistry.

\section{INTRODUÇÃO}

Tradicionalmente, o grau de desenvolvimento econômico e social de uma nação é indicado por índices que expressam a quantidade de riqueza gerada pelo país, sua distribuição e a qualidade de vida de sua população. ${ }^{1}$ Todavia, é possível admitir que a pesquisa em ciência e tecnologia também desempenha um papel importante para o desenvolvimento de um país. Em termos econômicos, verifica-se uma correlação positiva entre o produto interno bruto (PIB) de uma nação e a sua produção científica. ${ }^{2}$ No plano social, acredita-se que o desenvolvimento científico e tecnológico possa solucionar, por exemplo, problemas relacionados à saúde e ao meio ambiente, os quais são, em última instância, de ordem social. ${ }^{3}$ Dessa forma, é plausível considerar que o desenvolvimento da ciência deve ser uma das prioridades em um país que pretende progredir social e economicamente.

A química é uma ciência básica de vastas aplicações, gera conhecimento capaz de conectar outros campos do saber e, ao mesmo tempo, alavanca a expansão do conhecimento, provendo instrumentos tecnológicos e culturais transformadores. ${ }^{4}$ Como em qualquer campo da ação humana, tais realizações dependem de vigorosos investimentos em pesquisa e na formação de recursos humanos. Logo, dependem da valoração e do entendimento da sociedade sobre a química. No Brasil, a demanda por recursos humanos no setor químico se expressa, por exemplo, pela falta de aproximadamente 25 mil químicos e engenheiros químicos nas indústrias ${ }^{5}$ e de 55 mil professores de química nas escolas. ${ }^{6}$ Delineia-se, portanto, uma situação desafiadora e preocupante, considerando a significativa evasão nos cursos de graduação em química, especialmente na área de licenciatura. ${ }^{7}$ Situação similar é observada também na Europa, Estados Unidos e Japão, com reflexos na redução do número de alunos e também no fechamento de cursos. ${ }^{8}$

*e-mail: gamarson@iq.usp.br
Estes indicadores do prestígio social da química parecem estar vinculados à imagem pública negativa da química: ${ }^{9}$ são notórios os exemplos de associações de conotação negativa da palavra química, como "dependência química", "arma química", "pneumonia química" etc. Para alguns autores, ${ }^{10}$ uma visão distorcida da química pode ter sido reforçada por uma abordagem equivocada dessa ciência, com um ensino demasiadamente focado em aspectos teóricos, caracterizado pela memorização e pela falta de contextualização. Segundo Hartigns e Fahy, ${ }^{11}$ a simples menção à palavra "química" pode tornar um produto "impopular"; o termo "quimiofobia" (chemophobia), inclusive, foi proposto $^{12}$ para designar a aversão à química. Esse cenário desfavorável justifica a criação e a manutenção de programas para a melhoria da imagem pública da química, bem como de estudos que elucidem por quê, como e de onde se formam as opiniões sobre a química. ${ }^{13}$

Em um cenário mais amplo, Castelfranchi ${ }^{14}$ pondera que pesquisas sobre a percepção pública da ciência têm sido realizadas com o objetivo de investigar que fatores influenciam as atitudes, interesses e engajamento das pessoas em relação à ciência, mas que nenhum fator mostrou-se claramente determinante quando o assunto é a opinião das pessoas sobre ciência. Todavia, uma pesquisa sobre a percepção pública da ciência e da tecnologia no Estado de São Paulo indicou correlação entre o maior interesse por ciência, em geral, e o maior consumo de informação científica, avaliado, entre outros quesitos, pelo hábito de leitura de notícias de ciência em jornais. ${ }^{15}$ Esses resultados corroboram a importância da mídia como fonte de informações sobre assuntos científicos e o papel que ela exerce na construção da imagem pública da ciência. Em parte significativa dos estudos sobre a relação entre ciência e jornalismo, a química é tratada de forma indistinta de outros campos das ciências naturais ou mesmo sociais, recebendo destaque minoritário muitas vezes. ${ }^{16}$ Por outro lado, naqueles trabalhos nos quais a química tem maior destaque, o foco analítico restringe-se a temas muito específicos, como mudanças climáticas, ${ }^{17}$ alimentos geneticamente modificados ${ }^{18}$ e nanotecnologia. ${ }^{19}$ Faltam 
estudos sistemáticos mais abrangentes sobre a imagem pública da química nos jornais, tomada em seu sentido mais amplo.

Adicionalmente, se o interesse da população pela ciência está relacionado ao consumo de informação científica, é válido assumir que as ações de divulgação da ciência assumem um papel fundamental para aumentar tal interesse. Entretanto, a finalidade de se comunicar assuntos de ciência e tecnologia vai muito além dessa questão. Uma revisão dos motivos elencados para justificar a divulgação da ciência ${ }^{20}$ inclui os seguintes benefícios: 1 ) ao cidadão, com o intuito de melhorar seus conhecimentos, aumentar a credibilidade da pesquisa científica, contribuir para processos de tomada de decisão etc; 2) à nação, a fim de estimular a carreira científica, melhorar a formação dos trabalhadores, aumentar a competitividade do país etc; 3 ) à própria ciência, visando a incentivar a interdisciplinaridade, aumentar suporte financeiro, obter apoio social etc. Há de se considerar ainda outras questões relevantes, as quais fazem referência, por exemplo, a questões éticas, de satisfação pessoal do cientista e do direito do cidadão de saber como seu dinheiro está sendo gasto. As inúmeras justificativas para divulgar ciência (e, por inclusão, a química) ao público têm mobilizado divulgadores de ciência profissionais, pesquisadores que investigam a área de divulgação científica e cientistas que participam de iniciativas de divulgação paralelamente às suas pesquisas. $^{21}$

As considerações tecidas sobre ciência e desenvolvimento socioeconômico, bem como imagem pública negativa da química e a demanda social por químicos, conduzem a, pelo menos, três perguntas incontornáveis:

"Que imagem da química é publicizada nos meios de comunicação?" "Que ações podem ser encampadas para divulgar a química junto à sociedade?"

"Qual imagem pública que a comunidade científica química pretende publicizar?"

Considerando a abrangência e a complexidade dessas questões, neste trabalho os assuntos serão tratados a partir de dois estudos de caso. O primeiro deles traça um panorama da imagem pública da química em jornais de grande circulação no Estado de São Paulo, estado que reúne expressiva parcela da atividade industrial nacional, inclusive do setor químico. O estudo traz resultados da análise de textos publicados no período de 2008 a 2012 nos jornais Folha de $S$. Paulo e O Estado de S. Paulo, que somaram em 2012, juntos, mais de 530 mil exemplares impressos diários com alcance em vários estados brasileiros, afora a difusão via canais eletrônicos. ${ }^{22} \mathrm{O}$ segundo estudo de caso toma como objeto o projeto coordenado pela SBQ (Sociedade Brasileira de Química) para o Ano Internacional da Química, o qual promoveu diversas ações em benefício da educação, difusão e pesquisa em química em todo o Brasil. O caso das ações do AIQ será discutido em termos dos seus resultados gerais e de sua repercussão nos meios de comunicação de abrangências nacional e local.

A partir desses estudos, pretende-se fomentar a reflexão, entre os membros da comunidade química, sobre qual deve ser a imagem da química e do profissional da química, assim como quais devem ser os mecanismos adotados para ser alcançar, difundir e avaliar essa imagem de forma contínua. Em última instância, este trabalho aborda um dos maiores desafios de uma Química sem fronteiras, ${ }^{23} \mathrm{a}$ promoção da educação em química, em todos os níveis de ensino e para além do ambiente escolar e acadêmico. De forma mais ampla e ambiciosa, esse desafio trata da necessidade de alavancar a educação em química ao mesmo patamar de importância apresentado pela química como ciência e atividade econômica.

\section{IMAGEM PÚBLICA DA QUÍMICA}

Foram analisados os conteúdos publicados nos jornais Folha de S.
Paulo e O Estado de S. Paulo no período de 2008 a 2012. O material para análise foi selecionado a partir do sistema de busca dos portais eletrônicos desses jornais, utilizando-se a palavra-chave "química" como critério de busca. A partir dessa triagem, que resultou em 5541 notícias no total, realizou-se a análise e classificação de cada um dos conteúdos encontrados, considerando-se o texto e as mídias (fotografia, infografia, audio etc) associadas. Todos os conteúdos foram identificados quanto ao jornal, título e data de publicação. Os seguintes descritores foram utilizados na classificação das notícias: i) Grau de relevância da química; ii) Imagem da química; iii) Setor; iv) Implicações do conhecimento químico; v) Assinatura; vi) Conteúdo reportado; vii) Referência geográfica; viii) Título. Uma descrição mais detalhada das categorias encontra-se no Material Suplementar deste trabalho.

Neste estudo, foram desconsiderados os conteúdos publicados nos cadernos de "Economia" e "Educação". Isso porque se notou, durante a etapa de classificação, que a maior parte deles limitava-se a abordar, respectivamente, o desempenho econômico da indústria química e as provas de química nos exames vestibulares, o que poderia gerar distorções na análise dos resultados. Todas as notícias com grau de relevância da química maior que 0 foram classificadas segundo os descritores "assinatura", "referência geográfica", "conteúdo reportado" e "título'. Mas apenas os conteúdos com grau de relevância igual a 3 foram categorizados conforme os descritores "setor", "imagem" e "implicações do conhecimento químico". Os dados obtidos, incluindo a identificação das notícias e a sua classificação, foram compilados em uma planilha eletrônica. Os dados foram tratados de modo a se obter a frequência de ocorrência do descritor "grau de relevância da química", além das análises cruzadas entre: "imagem e setor"; "implicações do conhecimento químico e imagem"; "assinatura e setor"; "conteúdo reportado e referência geográfica" e "presença da palavra química no título e imagem". Os resultados foram discriminados por jornal.

\section{Destaque e imagem da química}

Excluídos os conteúdos dos cadernos de "Economia" e "Educação", foram identificadas 5005 notícias contendo a palavra "química" nos jornais O Estado de S. Paulo e Folha de S. Paulo no período de 2008 a 2012.

Quando se analisa a distribuição dos conteúdos segundo o grau de relevância da química, observa-se uma grande semelhança entre os perfis dos dois jornais. Os resultados apontam que, na maior parte das notícias (71\% para ambos os jornais), a palavra "química" apresenta grau de relevância nulo no contexto da notícia. Frequentemente, essa palavra encontra-se desprovida de sentido realmente químico, confirmando o seu uso excessivo como expressão popular, não raramente de caráter pejorativo. ${ }^{24} \mathrm{Em}$ outros casos, o significado da palavra química é irrelevante no contexto da notícia, constituindo um mero exemplo. Os demais conteúdos estão distribuídos de forma relativamente equilibrada entre os demais graus de destaque. Destaca-se, nesse ponto, que somente em $10 \%$ das notícias, aproximadamente, a química possui relevância máxima segundo os critérios de classificação empregados.

Quando se analisam as notícias com grau de relevância 3, especificamente, classificando as mesmas por setor de inserção da química, verifica-se que a área da ciência é aquela na qual mais se identificam notícias com alta relevância da química. Esse é um dos resultados apontados na Tabela 1. Por outro lado, a área da educação exibe o menor número de notícias com esse grau de relevância, posição que se manteria mesmo que fossem contabilizados os conteúdos da editoria "Educação".

Isso pode ser discutido a partir do fato de que a maior parte das notícias envolvendo educação e química remete ao universo das provas de ingresso aos cursos superiores ou às programações culturais, em 
Tabela 1. Correlação entre setor de inserção e imagem da química para os conteúdos analisados com grau de relevância igual a 3

\begin{tabular}{lcccccc}
\hline \multirow{2}{*}{ Setor } & \multicolumn{2}{c}{ Positiva } & \multicolumn{2}{c}{ Indefinida } & \multicolumn{2}{c}{ Negativa } \\
\cline { 2 - 7 } & $\mathrm{E}$ & $\mathrm{F}$ & $\mathrm{E}$ & $\mathrm{F}$ & $\mathrm{E}$ & $\mathrm{F}$ \\
\hline Ciência & 92 & 86 & 66 & 66 & 6 & 5 \\
Economia & 10 & 3 & 20 & 5 & 52 & 44 \\
Educação & 2 & 4 & 11 & 0 & 1 & 1 \\
Outros & 0 & 1 & 1 & 0 & 3 & 2 \\
\hline Total & 104 & 94 & 98 & 71 & 62 & 52 \\
\hline
\end{tabular}

E: O Estado de S. Paulo; F: Folha de S. Paulo. As co-ocorrências entre categorias estão salientadas em escala de tons de cinza.

que a química é retratada junto a outras disciplinas ou outras opções de lazer, reduzindo o grau de relevância da química. Pode-se atribuir o grande número de notícias abordando a química no contexto dos vestibulares à valorização de tais exames, o que, por sua vez, tende a se refletir em um currículo escolar mais voltado à preparação para o vestibular do que para a função social da escola..$^{25}$

A Tabela 1 mostra, ainda, que a imagem da química com grau máximo de relevância é muito mais positiva do que negativa. É preciso salientar que tal análise não necessariamente reflete a percepção pública química, influenciada por inúmeros fatores que não fazem parte do escopo dessa pesquisa. No presente trabalho, a imagem é avaliada sob a perspectiva de alguém com formação em química, diferentemente de alguns estudos na área (analisando ciências em geral) realizados por profissionais da comunicação. ${ }^{26}$ É interessante assinalar, portanto, que os resultados obtidos podem estar relacionados à condição de se reconhecer o conhecimento químico inserido em contextos diversos e, muitas vezes, positivos.

Outro resultado que se depreende da Tabela 1 são as correlações entre a imagem e o setor de inserção da química. Nota-se que as principais correlações indicadas são entre economia e imagem negativa e entre ciência e imagem positiva, para ambos os jornais. No primeiro caso, constata-se que as indústrias químicas e os produtos associados às mesmas apresentam uma imagem fortemente negativa. Nessas notícias, encontram-se muito mais referências explícitas à química, em que a palavra "química" surge como um qualificativo negativo (e.g. "substância química", em vez de simplesmente substância) ou é citada de modo indireto (e.g. "químicos", como um termo genérico). Tal questão é bem ilustrada pela notícia a seguir:

"[...] Documento de cientistas americanos mostra que não há estudos sobre a segurança da grande maioria das 80 mil substâncias usadas pela indústria. (...) Estudos recentes encontraram produtos químicos industriais no sangue do cordão umbilical. "Os bebês estão nascendo pré-poluídos", afirma o conselho [...]", extraído de "Relação entre químicos e câncer é subestimada" (O Estado de S. Paulo, 15/05/2010). ${ }^{27}$

A respeito dessa correlação, Laszlo $^{12}$ afirma que a indústria química tem se prestado, nas palavras do próprio autor, ao papel de "bode expiatório" em relação a inúmeros problemas que preocupam a sociedade, pois a responsabilidade por danos gerados por outras indústrias ou mesmo por ações individuais acaba incidindo sobre a indústria química.

Já na correlação entre ciência e imagem positiva, é possível hipotetizar que a imagem positiva da química dentro do contexto científico tenha relação com uma visão cientificista da ciência, segundo a qual a ciência sempre contribui para solucionar problemas ou compreendê-los melhor. ${ }^{28}$ Considerando que o conhecimento químico, muitas vezes, está presente de forma tácita nas notícias, pode-se supor que esse cientificismo acaba se estendendo à química também.
A imagem da química conforme a natureza das implicações do conhecimento químico é apontada na Tabela 2, que corrobora uma imagem preponderantemente positiva da química, quando analisada no contexto das pesquisas científicas. Quanto aos tipos implicações categorizadas, ressalta-se que a saúde aparece como a área de pesquisa que mais faz uso do conhecimento químico. A imagem da química, nesse caso, apresenta-se mais positiva, embora seja considerável o número de notícias em que a mesma é negativa.

Tabela 2. Correlação entre implicações do conhecimento químico e imagem da química para os conteúdos analisados com grau de relevância igual a 3

\begin{tabular}{lcccccc}
\hline \multirow{2}{*}{ Implicações } & \multicolumn{2}{c}{ Positiva } & \multicolumn{2}{c}{ Indefinida } & \multicolumn{2}{c}{ Negativa } \\
\cline { 2 - 7 } & $\mathrm{E}$ & $\mathrm{F}$ & $\mathrm{E}$ & $\mathrm{F}$ & $\mathrm{E}$ & $\mathrm{F}$ \\
\hline Saúde & 47 & 38 & 9 & 8 & 20 & 21 \\
Científico & 17 & 10 & 35 & 36 & 0 & 0 \\
Ambiental & 20 & 16 & 13 & 12 & 6 & 2 \\
Tecnológico & 14 & 12 & 1 & 0 & 0 & 0 \\
Econômico & 7 & 5 & 1 & 1 & 1 & 0 \\
Social & 1 & 3 & 6 & 1 & 1 & 1 \\
Outros & 7 & 13 & 2 & 3 & 0 & 1 \\
\hline Total & 113 & 97 & 67 & 61 & 28 & 25 \\
\hline
\end{tabular}

E: O Estado de S. Paulo; F: Folha de S. Paulo. As co-ocorrências entre categorias estão salientadas em escala de tons de cinza.

Frente ao destaque da saúde nas notícias, é válido considerar o que $\mathrm{Adam}^{29}$ discute sobre a interface entre a química e as outras ciências, com efeitos principalmente na área da saúde. Segundo o autor, o mérito por muitos dos progressos científicos é conferido a outras ciências que não a química, o que pode ser exemplificado pelas pesquisas com DNA, assumidas pela biologia, e pelo desenvolvimento dos exames de imagem por ressonância magnética, associado aos físicos. Apesar de considerar relevante o trabalho interdisciplinar, o autor pondera que é fundamental para a química buscar o reconhecimento de seus trabalhos, melhorando a imagem da química e atraindo mais estudantes para essa ciência.

A correlação entre imagem indefinida da química e implicações científicas também se destaca nos resultados apresentados, o que reforça a importância da química como ciência que gera conhecimento para outras áreas do saber se desenvolverem. Entretanto, sob outra perspectiva, esse mesmo quadro pode se tornar desfavorável. Uma vez que algumas pesquisas não apresentam consequências diretas e imediatas para a população, é possível que a química seja vinculada a estudos aparentemente sem utilidade, como adverte Brotero. ${ }^{30}$ Para a autora, quando uma notícia reporta que o conhecimento químico contribuiu para certa pesquisa e a mesma é relatada como uma mera curiosidade, a imagem da química pode ser prejudicada.

Outro resultado que chama a atenção é a baixa associação entre implicações ambientais e imagem negativa, ao contrário do que afirma o senso comum sobre a percepção pública da química. O que o resultado sugere, de fato, é que pesquisas voltadas para solucionar e entender problemas ambientais, com o auxílio da química, estão sendo feitas e os jornais têm divulgado esses estudos. A percepção negativa da química quando o assunto é meio ambiente pode decorrer, por sua vez, de outros tipos de notícias, mais relacionadas a acidentes e fatos pontuais do que ao meio científico propriamente.

Finalmente, ressalta-se a pouca evidência da química em estudos científicos que tenham consequências declaradas para outras áreas além da saúde, científica, ambiental e tecnológica. Essa baixa inserção da química contrasta com o seu perfil de ciência cujos conhecimentos têm implicações diversas nas vidas das pessoas. 


\section{Autoria, referencial geográfico e conteúdo das notícias}

Ao se analisar a autoria das notícias com grau de relevância 3 da química, observa-se que os créditos das matérias são atribuídos, em sua maior parte, às fontes externas, conforme mostra a Tabela 3. Dentre as fontes mais citadas, estão as agências de notícias BBC Brasil (British Broadcasting Corporation), Reuters, EFE, France Press e Associated Press.

Tabela 3. Correlação entre assinatura da notícia e setor de inserção da química para os conteúdos analisados com grau de relevância igual a 3

\begin{tabular}{lcccccccc}
\hline \multirow{2}{*}{ Assinatura } & \multicolumn{3}{c}{ Ciência } & \multicolumn{2}{c}{ Economia } & \multicolumn{2}{c}{ Educação } & \multicolumn{2}{c}{ Outros } \\
\cline { 2 - 9 } & $\mathrm{E}$ & $\mathrm{F}$ & $\mathrm{E}$ & $\mathrm{F}$ & $\mathrm{E}$ & $\mathrm{F}$ & $\mathrm{E}$ & $\mathrm{F}$ \\
\hline Fonte & 110 & 62 & 42 & 26 & 1 & 1 & 3 & 0 \\
Jornalista & 49 & 69 & 44 & 15 & 3 & 2 & 1 & 0 \\
N.I. & 13 & 26 & 4 & 12 & 10 & 2 & 1 & 3 \\
Especialista & 1 & 4 & 1 & 1 & 0 & 0 & 0 & 0 \\
Redação & 1 & 0 & 0 & 0 & 0 & 0 & 0 & 0 \\
\hline Total & 174 & 161 & 91 & 54 & 14 & 5 & 5 & 3 \\
\hline
\end{tabular}

E: O Estado de S. Paulo; F: Folha de S. Paulo; N.I.: Não identificada. As co-ocorrências entre categorias estão salientadas em escala de tons de cinza.

Quando se correlaciona a autoria dos conteúdos aos setores de inserção da química, encontra-se que a principal associação é entre fonte e ciência. Isso significa que muitas das notícias de ciência em que o destaque da química é alto são assinadas por fontes externas, ou seja, são matérias reproduzidas (parcial ou integralmente) a partir de outras fontes.

Esse resultado difere dos números encontrados por Amorim $^{31}$ ao investigar a cobertura de ciências por sete jornais da América Latina. Em sua pesquisa, o autor apontou menor destaque para as agências de notícias quando analisou a autoria das matérias. Porém, apenas o conteúdo da editoria de "Ciência" foi classificado em seu estudo, ao passo que neste trabalho não houve exclusão de editorias, com exceção dos cadernos de "Economia" e de "Educação". Um exemplo que pode explicar a diferença encontrada é o caderno "Mundo" do jornal Folha de S. Paulo, que contém várias matérias de ciências assinadas por agências de notícias.

Destaca-se ainda na tabela 3 o reduzido número de matérias assinadas por especialistas. Tal resultado concorda com aqueles encontrados por Bentley e Kyvik, ${ }^{32}$ que analisaram as publicações de cientistas de 13 diferentes países, incluindo o Brasil, considerando tanto as publicações científicas, voltadas a seus pares, quanto as populares, destinadas à população em geral e presentes em jornais e revistas. Em sua pesquisa, os autores apontaram que mais de $90 \%$ dos cientistas pesquisados informaram ter publicado ao menos um artigo científico de 2005 a 2007, mas apenas um terço deles publicou um artigo popular. A razão entre artigos populares e científicos foi mais baixa entre pesquisadores da área de ciências naturais. Uma das hipóteses levantadas pelos autores para explicar os resultados obtidos é a falta de compensações e incentivos dos pesquisadores para escrever matérias em jornais e revistas.

No cenário nacional, uma pesquisa sobre percepção pública da ciência realizada com 70 pesquisadores da Universidade Federal de São Carlos (UFSCar) também revelou a baixa participação dos cientistas em ações direcionadas à divulgação da ciência. ${ }^{33}$ Apesar de $30 \%$ dos entrevistados apontarem os próprios cientistas como sendo os principais responsáveis pela divulgação científica ao público não especialista, menos da metade dos pesquisadores afirmou ter participado, em 2008, de atividades em âmbito não acadêmico, como palestras para o público não especialista, entrevistas em rádio e televisão, além de publicações em jornais e revistas. Ademais, para $57 \%$ dos entrevistados, a linguagem constitui a maior dificuldade do público leigo para entender assuntos de ciência e tecnologia.

Diante desses dados, é possível assumir que a percepção pública da ciência pode ser influenciada pela discreta atuação dos cientistas em atividades de divulgação científica, especialmente quando se trata de química, considerada uma ciência complexa e marcada por percepções negativas. Nesse contexto, convém ressaltar que a falta de divulgação da química por aqueles que são especialistas na área pode ter reflexos negativos para a imagem da química, à medida que outras pessoas, sem formação na área, passam a tecer comentários sobre assuntos químicos, definindo e caracterizando essa ciência de acordo com os seus conhecimentos e impressões sobre a mesma. ${ }^{34}$

Quando a análise das notícias refere-se ao seu contexto geográfico, observa-se que este é internacional, sobretudo, enquanto conteúdos que fazem menção a questões nacionais aparecem em segundo lugar, como mostra a Tabela 4. Esta indica, ainda, que as pesquisas são os conteúdos reportados com maior frequência, seguidos dos conteúdos que reportam fatos e suas repercussões.

Tabela 4. Correlação entre tipo de conteúdo reportado e referência geográfica para os conteúdos analisados com grau de relevância maior que zero

\begin{tabular}{lccccccc}
\hline \multirow{2}{*}{ Conteúdo reportado } & \multicolumn{3}{c}{ Nacion. } & \multicolumn{2}{c}{ Internac. } & \multicolumn{2}{c}{ Outros } \\
\cline { 2 - 7 } & $\mathrm{E}$ & $\mathrm{F}$ & $\mathrm{E}$ & $\mathrm{F}$ & $\mathrm{E}$ & $\mathrm{F}$ \\
\hline Pesquisa & 42 & 47 & 228 & 192 & 8 & 7 \\
Fato ocorrido & 45 & 32 & 49 & 45 & 25 & 10 \\
Repercussões de fato & 53 & 39 & 38 & 32 & 6 & 12 \\
Desenv. Tecnológico & 22 & 19 & 35 & 33 & 5 & 3 \\
Alerta de risco & 7 & 12 & 8 & 18 & 11 & 9 \\
Políticas públicas & 30 & 9 & 11 & 7 & 6 & 2 \\
Programação cultural & 3 & 15 & 1 & 2 & 2 & 1 \\
Opinião & 13 & 7 & 1 & 1 & 4 & 4 \\
Outros & 72 & 46 & 34 & 30 & 98 & 63 \\
\hline Total & 287 & 226 & 405 & 360 & 165 & 111 \\
\hline
\end{tabular}

E: O Estado de S. Paulo; F: Folha de S. Paulo; Nacion.: Nacional; Internac.: Internacional; Desenv. Tecnológico: Desenvolvimento Tecnológico. As coocorrências entre categorias estão salientadas em escala de tons de cinza.

Esses dados, particularmente, contemplam todas as notícias analisadas, exceto aquelas com grau de relevância nulo. A partir disso, vale salientar que, em muitas das notícias a respeito de fatos e repercussões, o destaque da química foi considerado baixo, motivo pelo qual a imagem da química não foi analisada. Porém, notícias sobre acidentes em indústrias e casos de contaminação, por exemplo, tendem a repercutir muito mais na imprensa do que pesquisas e notícias de caráter positivo. Supõe-se então que a referência à química, mesmo que discreta, nesses tipos de conteúdos, poderia maximizar percepções negativas por parte do público geral, hipótese que poderia ser mais bem avaliada em outros estudos.

Outro resultado também apresentado na Tabela 4 é a correlação entre a referência geográfica das notícias e o tipo de conteúdo reportado. Enquanto fatos e repercussões referem-se mais a questões nacionais, as pesquisas reportadas são, majoritariamente, internacionais. Na pesquisa de Amorim, ${ }^{31}$ os estudos científicos internacionais também se destacaram mais que os nacionais em dois dos três jornais brasileiros analisados. Entrevistados pelo pesquisador, os editores desses jornais (Folha de S. Paulo e $O$ Globo) argumentaram que o destaque da pesquisa internacional estaria relacionado à reduzida 
contribuição do Brasil para a pesquisa mundial e ao fato de que pesquisas estrangeiras relevantes não poderiam ser ignoradas.

Ainda que ambos os argumentos sejam pertinentes, é inevitável questionar os efeitos da cobertura limitada dos estudos científicos nacionais, envolvendo o desprestígio da ciência nacional e todas as consequências que podem advir disso. Acerca da importância das pesquisas estrangeiras, também cabe questionar até que ponto tal avaliação não está associada ao desconhecimento das pesquisas brasileiras. Essa proposição é validada pela notícia a seguir:

“[...] Professores universitários e cientistas de relevância mundial em nanotecnologia, química de produtos naturais e química verde [...]", extraído de "Químicos brasileiros, padrão internacional" (O Estado de S. Paulo, 27/06/2011). ${ }^{35}$

Ao apresentar o perfil profissional e a linha de pesquisa de três renomados químicos brasileiros, a matéria prestigia a pesquisa nacional na área química. Entretanto, o próprio título do texto parece sugerir uma surpresa em relação à qualidade dessa pesquisa. É interessante notar que a matéria foi publicada na ocasião do Ano Internacional da Química, o que pode ter servido de motivação para a pauta do jornal.

\section{Química explícita versus química implícita}

Analisando as notícias que contêm a palavra "química", percebe-se que as visões de química presentes nos textos são diversas, ora mais explícitas, ora mais implícitas. As matérias a seguir ilustram a complexidade dessa análise:

1. "[...] A nova droga produzida a partir do açafrão-do-prado ( $\mathrm{Col}$ chicum autumnale) circula na corrente sanguínea, mas só é ativada por uma substância química emitida por tumores malignos. [...]", extraído de "Droga com flor do Egito antigo combate câncer em cobaias" (Folha de S. Paulo, 24/06/2011). ${ }^{36}$

2. "[...] Entre os pontos da lei que o secretário apontou como imprecisos está o trecho que proíbe pesquisas com "substâncias químicas". "Tudo é substância química. Até a água, que contém hidrogênio e oxigênio", comentou [...]", extraído de "Lei das Cobaias é 'inexequíivel', diz secretário do RJ" (O Estado de S. Paulo, 04/01/2008). ${ }^{37}$

3. “[...] Sempre haverá um químico criativo que conseguirá ampliar o poder de drogas e o gosto de alimentos com características nutricionais suspeitas [...]", extraído de "Tabaco sem gosto" (Folha de S. Paulo, 22/03/2012). ${ }^{38}$

No primeiro exemplo, a química está presente já no título, uma vez que a droga é uma substância "química". Porém, apesar de o conhecimento químico ser importante para a pesquisa reportada, a palavra "química", citada somente uma vez, aparece dentro de um contexto que pode ser considerado negativo, pois se refere a uma substância emitida por tumores malignos. Logo, o texto pode sugerir que as "substâncias químicas" são danosas para a saúde, diferentemente das drogas (em contexto médico), fármacos e remédios, que melhoram a saúde.

Na segunda matéria, destaca-se que a lei criticada pelo Secretário Estadual de Ciência e Tecnologia do Rio de Janeiro revela o desconhecimento do que seria uma "substância química" por parte de quem elaborou o texto, haja vista a associação implícita entre "química" e "substância tóxica". Essa concepção equivocada da química, evidenciada pelo comentário do secretário, demonstra que ações de divulgação da química, assim como de outras ciências, podem ter inúmeras implicações, gerando impacto inclusive político. ${ }^{39}$

No último exemplo, a imagem da química sugerida pelo texto é, explicitamente, negativa. Em um trecho particular da matéria, o autor atribui aos químicos a capacidade de modificar substâncias. Embora correta, essa informação assume uma conotação negativa, à medida que vincula o trabalho de síntese química a atividades escusas.
A visibilidade da "química" no conteúdo reportado tende a ser maior quando a palavra "química" encontra-se no título da notícia. Quando se correlaciona a presença da palavra "química" no título e a imagem da mesma na notícia, os resultados apontam que a palavra "química", uma vez presente, faz parte de notícias de caráter positivo geralmente. Todavia, metade das notícias positivas com a palavra "química" no título reporta conteúdos relacionados ao Prêmio Nobel de Química, em um contexto bastante científico e, por consequência, restrito do ponto de vista da divulgação da ciência.

A imagem da química apresentada em jornais do Estado de São Paulo sugere um distanciamento entre a imagem difundida para a população em geral e aquela que representaria a química de fato. A invisibilidade da química e eventuais imprecisões e distorções de sua imagem poderiam ser minimizadas por iniciativas promovidas no sentido melhorar a difusão e a imagem pública da química. É nesse contexto, portanto, que se insere o projeto AIQ - Ano Internacional da Química 2011, cujas ações e implicações serão discutidas a seguir.

\section{AÇÕES DO PROJETO AIQ}

No contexto comemorativo do Ano Internacional da Química, instituído pela Organização das Nações Unidas em 2011, o projeto AIQ patrocinou inúmeras ações comemorativas em prol da educação e da pesquisa em química no Brasil. Esse empreendimento foi coordenado por órgãos representativos da Química Brasileira e apresentou como principais metas: i) fomentar o conhecimento e a educação química em todos os níveis; ii) celebrar os benefícios da química para o progresso da humanidade; iii) promover a reflexão sobre o papel da química na construção de um mundo sustentável; iv) congregar a comunidade química brasileira em torno de ações favoráveis ao Programa Nacional de Ciência e Tecnologia. ${ }^{40}$

O projeto AIQ foi financiado pela iniciativa privada e pelo governo federal. Na esfera pública, o Ministério de Ciência e Tecnologia (MCT) concedeu verba para o pagamento de diárias, passagens e serviços terceirizados, que custaram pouco mais de $\mathrm{R} \$ 1,6$ milhão.

Em parceria com representantes da comunidade científica, do setor empresarial e do governo, o AIQ colaborou no desenvolvimento, organização e difusão de iniciativas diversas, apresentados e discutidos a seguir em termos de diferentes indicadores de desempenho.

Dentre as ações promovidas pelo projeto AIQ, as exposições destacam-se pela abrangência do público alvo e pelo grande número de pessoas atendidas. Em conjunto com a SBQ, o AIQ viabilizou e participou da criação de três grandes exposições. Duas destas exposições, "Elementar - A Química que faz o mundo" e "Cadê a química?", foram inicialmente apresentadas no Rio de Janeiro e seguiram em itinerância desde então. A terceira, "Química para um mundo melhor", foi realizada em São Paulo em 2011 e teve um total de 43 inserções na imprensa (televisão, jornal, rádio, blogs e web sites), sendo nove com entrevista, o que demonstra a visibilidade que o evento obteve nos meios de comunicação. No total, essas três exposições tiveram um público estimado de 79 mil visitantes. Já a exposição "Química no Cotidiano", que expôs painéis temáticos abordando a inserção da química em nosso dia a dia, somou 350 apresentações pelo Brasil. Todas as exposições resultaram em inserções na mídia. A Tabela 5 sumariza dados selecionados sobre as exposições.

Exposições para a difusão da química entre estudantes também foram organizadas em edições da RASBQ (Reunião Anual da Sociedade Brasileira de Química) de 2011 e 2012, atendendo ao público de Florianópolis e Águas de Lindoia, respectivamente. Tais exposições ampliaram o impacto da RASBQ para além de sua importância científica, à medida que o evento representou uma oportunidade valiosa de aproximar estudantes e público em geral da comunidade química e do conhecimento gerado pela mesma. Em relação à $34^{\mathrm{a}} \mathrm{RASBQ}$, 
Tabela 5. Público alvo e indicadores de desempenho das ações do Projeto AIQ: Exposições

\begin{tabular}{lcl}
\hline Ações & Público alvo & Indicadores de desempenho \\
\hline $\begin{array}{l}\text { Painéis sobre Química no Co- } \\
\text { tidiano }\end{array}$ & EG, PG & $\begin{array}{l}350 \text { apresentações em todos } \\
\text { os estados }\end{array}$ \\
\hline $\begin{array}{l}\text { Elementar - A Química que faz } \\
\text { o mundo }\end{array}$ & EG, PG & 13,2 mil visitantes \\
\hline Química para um mundo melhor & EG, PG & 45 mil visitantes \\
\hline Cadê a química? & EG, PG & 20,3 mil visitantes \\
\hline
\end{tabular}

EG: Estudantes em geral; PG: Público em geral.

cabe citar ainda o evento "Mulheres na Ciência", no qual a SBQ celebrou o trabalho de mulheres vencedoras do prêmio Nobel em Química e ressaltou a competência e o profissionalismo de pesquisadoras renomadas no cenário brasileiro, conferindo às pesquisadoras homenageadas o prêmio "Marie Curie". Tal ação merece destaque por propor uma ação de divulgação sobre cientistas, por cientistas e para cientistas, o que constitui um modelo de proposição de ações que possam favorecer a reflexão de questões ligadas à ciência e à divulgação da ciência entre cientistas. Adicionalmente, é razoável admitir que o reconhecimento de mérito associado à premiação pode favorecer a valoração positiva deste tipo de iniciativa pela comunidade de cientistas.

Materiais paradidáticos e de divulgação da química também tiveram um grande alcance junto ao público, considerando suas versões impressas e digitais. A coleção de livros "Química no Cotidiano" inclui nove títulos que tratam dos mais diferentes temas, como saúde, energia e alimentos, por exemplo. A experimentação em química, por sua vez, é contemplada nos livros "A química mais perto de você", com propostas de experimentos voltadas para estudantes de diferentes níveis de ensino, do fundamental à graduação. Além disso, foi lançado um DVD comemorativo contendo os livros e a coleção "Química Nova na Escola". Centenas de cópias desses livros foram distribuídas, milhares de acessos à versão digital foram contabilizados e outros milhares de DVDs foram disponibilizados para as escolas. Esses materiais também foram enviados para outros países de língua portuguesa, ampliando o alcance dessas ações. Ainda foram desenvolvidos materiais paradidáticos e de divulgação em parceria com a ACS (American Chemical Society) e a revista "Ciência Hoje", respectivamente. Alguns destes dados são mostrados na Tabela 6.

O AIQ também apoiou projetos de naturezas diversas. A união entre arte e química foi promovida pelo projeto "Lumini", abordando

Tabela 6. Público alvo e indicadores de desempenho das ações do Projeto AIQ: Produção de material paradidático e de divulgação

\begin{tabular}{lcl}
\hline Ações & Público alvo & Indicadores de desempenho \\
\hline $\begin{array}{l}\text { "DVD comemorativo" contendo } \\
\text { livros e coleção completa da } \\
\text { revista Química Nova na Escola }\end{array}$ & PEFM & 80 mil exemplares \\
\hline $\begin{array}{l}\text { Coleção Química no Cotidiano } \\
\text { (versão impressa) }\end{array}$ & EEFM & 500 cópias \\
\hline $\begin{array}{l}\text { Tradução e confecção de cader- } \\
\text { nos temáticos em parceria com }\end{array}$ & EEF & 6 cadernos desenvolvidos \\
a ACS, "Celebrating Chemistry" & & \\
\hline $\begin{array}{l}\text { Vídeo de animação em tecno- } \\
\text { logia 3D - História química da } \\
\text { humanidade }\end{array}$ & EG & $\begin{array}{l}\text { Conteúdo exibido na ex- } \\
\text { posição "Cadê a química?" }\end{array}$ \\
\hline
\end{tabular}

EG: Estudantes em geral; EEF: Estudantes do Ensino Fundamental; EEFM: Estudantes do Ensino Fundamental e Médio; PEFM: Professores do Ensino Fundamental e Médio; PG: Público em geral. o conceito de luminescência no contexto de um espetáculo de dança. Outro projeto foi o "365 dias de Química”, uma parceria do programa de pós-graduação em Química da UFRJ com o portal QNInt (Química Nova Interativa) e a diretoria da SBQ. Desenvolvido em 2011, o projeto disponibilizou, diariamente, uma entrevista com um profissional da área química, professor, pesquisador ou profissional da indústria, além de exibir representações interativas de moléculas 3D acompanhadas de um texto contextualizado. Tais representações são recursos de visualização originalmente desenvolvidos para o portal QNInt, que já reúne mais de 350 moléculas em seu acervo, com média aproximada de 900 acessos por molécula. ${ }^{41}$

Em nível mundial, o Brasil participou, por meio do AIQ, do "Experimento global da água - pH do planeta", proposto com o objetivo de medir o $\mathrm{pH}$ de amostras de água de todo o mundo. O AIQ viabilizou a distribuição para as escolas de mais de 38 mil kits para medição do $\mathrm{pH}$ da água, material que foi produzido por universidades (UFBA e Unicamp) e pela iniciativa privada (empresa CQA- SP). $\mathrm{O}$ projeto mobilizou milhares de estudantes em todo o Brasil e os resultados dos 2,9 mil experimentos puderam ser acompanhados em tempo real pelo portal QNInt. Esse experimento também foi realizado em eventos nos quais o AIQ marcou presença, tais como a Semana Nacional de Ciência e Tecnologia, em outubro de 2011, com o tema "Mudanças Climáticas e Desastres Ambientais", e a Rio+20, Conferência das Nações Unidas sobre Desenvolvimento Sustentável, em junho de 2012 no espaço Pop Ciência, no qual a SBQ convidou a população a analisar a água que consome por meio do projeto $\mathrm{pH}$ do planeta.

Reuniões e encontros também fizeram parte do AIQ, como mostra a Tabela 7. Em maio de 2012, a SBQ organizou o evento "Encontro ciência e jornalismo - A Química em pauta", voltado a pesquisadores, jornalistas e divulgadores de ciência, com a finalidade de confrontar e discutir as relações entre a ciência e o público, além de desmistificar a química frente aos jornalistas e divulgar assuntos da área que poderiam ser cobertos por esses profissionais. ${ }^{42} \mathrm{Em}$ parceria com a FAPESP e a SBQ, foi realizado ainda um Ciclo de Seminários em comemoração ao Ano Internacional da Química. Denominado "Nossa vida, nosso futuro", o evento discutiu, por meio de 10 seminários temáticos, o papel da química para um desenvolvimento sustentável.

Tabela 7. Público alvo e indicadores de desempenho das ações do Projeto AIQ: Encontros

\begin{tabular}{|c|c|c|}
\hline Ações & Público alvo & Indicadores de desempenho \\
\hline $\begin{array}{l}7^{\circ} \text { Encontro do fórum na- } \\
\text { cional de coordenadores de } \\
\text { cursos de graduação }\end{array}$ & CCG & $\begin{array}{l}110 \text { representantes das } \\
\text { regiões brasileiras partici- } \\
\text { param do fórum }\end{array}$ \\
\hline $\begin{array}{l}\text { Encontro da SBQ com o } \\
\text { ensino básico do estado de } \\
\text { Santa Catarina }\end{array}$ & $\begin{array}{l}\text { EEFM } \\
\text { PEFM }\end{array}$ & $\begin{array}{l}36 \text { municípios com escolas } \\
\text { participantes }\end{array}$ \\
\hline $\begin{array}{l}\text { Ciclo de seminários Fapesp } \\
\text { comemorativo ao Ano Inter- } \\
\text { nacional da Química }\end{array}$ & $\begin{array}{c}\mathrm{C} \\
\mathrm{PG}\end{array}$ & $\begin{array}{l}10 \text { seminários com } 28 \text { con- } \\
\text { ferencistas de todo Brasil }\end{array}$ \\
\hline
\end{tabular}

CCG: Coordenadores de cursos de graduação; EEFM: Estudantes de Ensino Fundamental e Médio; PEFM: Professores de Ensino Fundamental e Médio; C: Cientistas; PG: Público em geral.

No contexto do ensino superior, a SBQ promoveu um encontro entre coordenadores de cursos de graduação, com foco na formação do químico e do docente de Química nos diversos níveis da educação brasileira. Entre seus resultados, os grupos deram especial destaque às proposições de ações locais/regionais dos cursos de graduação em Química, considerando a importância de sua continuidade e de seus efeitos em longo prazo. No nível básico de ensino, a educação 
em química para os níveis fundamental e médio foi discutida com especialistas na área em Santa Catarina, em um encontro organizado pelo CRQ 13ª Região e pela Secretaria de Educação de Santa Catarina.

A reunião de jovens em torno das comemorações do Ano Internacional da Química ocorreu ainda por meio de concursos como "A Química através da câmera", modalidades vídeo caseiro e fotografia, e "Logotipo do AIQ", que elegeu um selo representativo do projeto AIQ a partir de um concurso aberto na internet. Com um público alvo mais diversificado, o concurso "O legado da Rio+20: que futuro queremos?" envolveu estudantes de todos os níveis de ensino, com o objetivo de incentivar o desenvolvimento de projetos que contemplassem a importância da Química na construção de um mundo sustentável. Em continuidade às ações do AIQ, a SBQ lançou neste ano os "Desafios QNInt", um concurso que tem como tema a valorização da química para o progresso humano. Estudantes de todos os níveis de ensino podem participar do concurso enviando músicas, paródias ou vídeos sobre o tema. Em Santa Catarina, o AIQ incentivou a educação em química ao apoiar a Olimpíada catarinense de Química 2011, com a criação de um site para disponibilizar todo o material da olimpíada catarinense de química, assim como o material de suporte para a preparação dos estudantes.

$\mathrm{Na}$ internet, as informações sobre as atividades realizadas em comemoração ao Ano Internacional da Química no Brasil foram centralizadas no portal AIQ. Nele, foram informadas todas as ações patrocinadas pelo projeto do AIQ, bem como ações realizadas pelos órgãos parceiros, como os Conselhos Regionais de Química, Associação Brasileira da Indústria Química - ABIQUIM, centros de pesquisas, universidades, empresas parceiras e escolas de ensino médio e fundamental. Ações de divulgação da química nas escolas foram apresentadas na sessão "AIQ nas escolas" e eventos diversos em comemoração ao Ano Internacional da Química foram divulgados na sessão "Eventos". O projeto "365 dias de Química” também estava presente no portal. Além disso, foram disponibilizadas para download as coleções de livros do AIQ, bem como os painéis temáticos da exposição "Química no Cotidiano". Essa iniciativa rendeu milhares de downloads dos materiais paradidáticos e de divulgação do AIQ, alcançando um enorme público de pessoas. Desde sua criação, já foram contabilizadas mais de 620 mil visitas ao portal AIQ. É importante ressaltar que a articulação das novas tecnologias da informação e do conhecimento com ações do AIQ demonstraram a função potencializadora da difusão das ações de divulgação científica. Um estudo publicado recentemente em Química Nova indica que o sucesso observado na edição brasileira do Experimento Global da Água foi facilitado pelo uso do portal QNInt para difusão e participação efetiva de comunidades escolares em diversas regiões do país. ${ }^{41}$

Apresentados todos os resultados relacionados ao AIQ desde 2011, pode-se afirmar que esse projeto representou não apenas um marco comemorativo, por ocasião do Ano Internacional da Química, mas também um conjunto de ações políticas voltadas para promover a educação e pesquisa em química no Brasil. Livros e outros materiais distribuídos e apresentados em eventos por todo o Brasil estão entre os produtos gerados a partir do projeto. Outros produtos incluem todo o conhecimento químico difundido entre a população em geral, bem como a reflexão sobre a importância da química para o desenvolvimento social.

Em conexão com o estudo de caso sobre a imagem pública da química delineada nos jornais do Estado de São Paulo, é pertinente considerar dados disponíveis sobre a difusão na imprensa das ações do AIQ durante o ano de 2011.

Ao longo de 2011, foram identificadas 1001 referências positivas ao "Ano Internacional da Química” em veículos da imprensa de todo o país, incluindo emissoras de rádio, televisão, jornais, revistas, informativos de órgãos químicos, blogs e web sites diversos. A origem geográfica dessas publicações foi igualmente diversa, com representação de cidades do interior e de grandes capitais, de todas as regiões do país. Em relação aos dados apresentados no estudo de caso envolvendo dois jornais de grande circulação, é relevante destacar que há uma parcela relevante destas referências oriundas de centros regionais.

Finalmente, a partir do projeto AIQ, é possível delinear um modelo de divulgação da química que congregue e articule diferentes atores em torno de ações de divulgação contextualizadas, com suporte financeiro e avaliação sistemática. Os resultados positivos quanto à abrangência e à natureza das ações indicam que tal modelo pode ser uma proposta valiosa para encampar ações capazes de interferir positivamente no cenário identificado no primeiro caso discutido neste trabalho. De forma mais detalhada, é importante, dentro desse modelo, que as ações desenvolvidas estejam inseridas em um contexto de acordo com sua finalidade. No caso do AIQ, o projeto buscou promover a educação e pesquisa em química sob o tema "Química para um Mundo Melhor". Os atores engajados nessas ações incluem:

i) Gestores e articuladores - Entidades nacionais e regionais representativas da comunidade química, em seus diversos setores de inserção, como a SBQ, a ABIQUIM e os CRQs;

ii) Coordenadores e efetuadores - Membros de instituições de pesquisa, centros de divulgação de ciência e órgãos governamentais de diferentes localidades que planejem, coordenem e ajudem a executar, em nível local, as ações de divulgação, além de atuar na distribuição dos recursos disponíveis aos projetos existentes. O AIQ contou com a colaboração de inúmeras instituições, entre universidades, museus e Secretaria Estadual de Educação.

iii) Divulgadores - Profissionais da comunicação que propiciem a interlocução entre gestores/articuladores e coordenadores/efetuadores, além de promover as ações desenvolvidas junto à mídia. Em relação ao AIQ, essa tarefa foi desempenhada pela empresa "Allcomm Partners", por meio da ABIQUIM.

Para serem desenvolvidas, todas as ações precisam ser patrocinadas, seja pela iniciativa privada, seja pelo poder público. Quanto aos investimentos privados, devem ser feitos por empresas e indústrias, da área química (diretamente interessadas em ações de divulgação da química) ou de outras áreas (que tenham interesse em vincular sua imagem a ações de promoção da educação). Na esfera pública, o suporte financeiro deve partir do Ministério de Ciência e Tecnologia e das agências de fomento à pesquisa (CNPq, Faps etc), por meio do lançamento de editais destinados exatamente ao desenvolvimento de ações de divulgação da química. Tais editais, de fato, apenas atenderiam a demanda já existente por projetos de divulgação de ciência existentes em razão dos INCTs (Institutos Nacionais de Ciência e Tecnologia).

É fundamental ainda, neste modelo, que sejam pensadas formas de avaliação das ações promovidas, no sentido de avaliar a consecução dos objetivos propostos, as suas implicações e a possibilidade de aperfeiçoá-las.

\section{CONSIDERAÇÕES FINAIS}

Os estudos de caso apresentados trazem à luz desafios e oportunidades que engendram a imagem pública e a divulgação da química. A análise de textos de jornais indica que a imagem da química não pode ser simplesmente classificada como positiva ou negativa por pelo menos duas razões. Em primeiro lugar, essa categorização não refletiria a complexidade da química como área do saber nem como área profissional; segundo, as múltiplas inserções da química nos conteúdos jornalísticos, ora explicitadas pelo termo "química", ora subentendidas pelo contexto mais amplo, indicam diferentes níveis de visibilidade da química, de acordo com os diferentes públicos de 
leitores e seus diferentes níveis de conhecimento da química. Indo além do senso comum, este estudo também aponta a necessidade e a possibilidade de ampliação do espaço da química juntos aos meios de comunicação, considerando fatores como a discreta divulgação da pesquisa química brasileira e a divulgação de informações equivocadas referentes à química.

Para aumentar a visibilidade da química, tornam-se fundamentais ações de divulgação da química que envolvam membros da comunidade científica. Entretanto, iniciativas isoladas de pesquisadores, embora tenham seu valor, apresentam um impacto consideravelmente menor do que ocorreria se as ações fossem integradas e articuladas segundo um modelo de divulgação como observado no projeto AIQ, no qual a coordenação em diversos níveis, nacional, regional e local, somada ao contato próximo com a imprensa e o suporte financeiro, gerou resultados expressivos em termos de promoção da educação e pesquisa em química. É preciso ressaltar, contudo, que resultados em longo prazo, com benefícios significativos aos cidadãos, à nação e à ciência, somente são possíveis se as ações para divulgar a química forem constantes.

As instituições de ensino superior encontram um desafio e uma oportunidade no processo de mobilização de recursos humanos e na valorização de ações de difusão como o AIQ, sobretudo as instituições públicas, as quais sustentam a produção de conhecimento em química. A oportunidade e o desafio estão contidos no compromisso institucional de oferecer pesquisa, ensino e extensão à sociedade. Para que possam responder satisfatoriamente às questões do mundo contemporâneo, as universidades devem repensar as métricas de avaliação da produção de seus docentes, de modo a reafirmar e cumprir, de forma equilibrada, o compromisso com a formação de recursos humanos, a produção de conhecimento e as relações extramuros com a sociedade. A exemplo do sistema que foi construído para a pesquisa, isso requer instrumentos de coleta de dados e de avaliação das atividades de divulgação da química. Com efeito, já existe incorporada na base de currículos Lattes seção dedicada a coletar a produção de divulgação da ciência. Em grandes projetos de pesquisa desenvolvidos em redes de pesquisadores, já se faz necessário contemplar alíneas destinadas ao ensino e a divulgação das ciências. Contudo, ainda carecemos de ações efetivas para que essas iniciativas e seus produtos sejam levados em devida conta no desenvolvimento profissional de seus atores.

Movimento paralelo e análogo pode ser favorecido no âmbito do sistema básico de ensino e das organizações de profissionais da química, já que qualquer iniciativa gerada nas universidades não terá voz sem a participação destes agentes. Por questões evidentes, a perenização dessas ações depende de iniciativas que favoreçam a inserção de ações de divulgação científica no locus da escola, e, também, favoreçam o acesso da comunidade escolar ao locus da pesquisa em química. Neste quesito, as ações de divulgação da química têm se beneficiado sistematicamente das ações encampadas pela comunidade de ensino de química, seja na formação inicial e continuada de professores, seja na proposição e elucidação de questões investigativas educacionais. Contudo, permanecem pouco exploradas no Brasil outras formas de valorização dos atores de divulgação, como o reconhecimento de mérito por meio de premiações. Nos Estados Unidos, por exemplo, tanto a ACS quanto a Associação Americana para o Avanço da Ciência (AAAS) mantêm premiações anuais para membros da comunidade de destacada contribuição no ensino e na divulgação da ciência.

Finalmente, há de se considerar que o desenvolvimento de ações de divulgação e de pesquisa sobre a imagem pública da química requer que a comunidade química defina uma identidade para a química e para os profissionais da área, pois a caracterização da imagem da química e as iniciativas para divulgá-la são ações menos eficazes na ausência de uma identidade que sirva como referencial, seja para comparações entre a imagem pública e a "ideal", seja como um norte que oriente as ações de divulgação. Essa reflexão deve ocorrer e se fortalecer dentro da comunidade química, a qual, além de definir tal identidade, precisa também desenvolver mecanismos que permitam avaliar, permanentemente, a imagem pública da química, bem como o êxito das ações de divulgação.

\section{MATERIAL SUPLEMENTAR}

No material suplementar, encontra-se a caracterização dos descritores empregados na classificação dos conteúdos jornalísticos. É apresentada a definição de cada descritor, além de serem citadas as categorias previstas para cada um deles.

\section{REFERÊNCIAS}

1. PNUD (Programa das Nações Unidas para o Desenvolvimento); Relatório do Desenvolvimento Humano 2013 - A Ascenção do Sul: Progresso Humano num Mundo Diversificado, 2013.

2. King, D. A.; Nature 2004, 430, 311.

3. Annan, K.; Science 2004, 303, 925.

4. <http://www.chemistry2011.org/introductiontochemistry>, acessada em Maio 2013.

5. <http://rmai.com.br/v4/Read/1297/dia-do-quimico-chega-com-demandacrescente-por-profissionais-da-area.aspx $>$, acessada em Maio 2013.

6. <http://portal.mec.gov.br/cne/arquivos/pdf/escassez1.pdf>, acessada em Maio 2013

7. Zucco, C.; Quim. Nova 2007, 30, 1429.

8. Editorial; Nature Materials 2006, 5, 671.

9. Hartings, M. R.; Fahy, D.; Nature Chemistry 2011, 3, 674; Editorial; Nature 2001, 411, 399; Knight, D. Em The Public Image of Chemistry; Schummer, J.; Bensaude-Vincent, B.; Van Tiggelen, B., eds.; World Scientific Publishing Co. Pte. Ltd.: Singapore, 2007, cap. 5; Ferreira, V. F.; Quim. Nova 2007, 30, 255; Laszlo, P. Em The Public Image of Chemistry; Schummer, J.; Bensaude-Vincent, B.; Van Tiggelen, B., eds.; World Scientific Publishing Co. Pte. Ltd.: Singapore, 2007, cap. 12.

10. Arroio, A.; Honório, K. M.; Weber, K. C.; Homem-de-Mello, P.; Gambardella, M. T. P.; da Silva, A. B. F.; Quim. Nova 2006, 29, 173.

11. Hartings, M. R.; Fahy, D.; Nature Chemistry 2011, 3, 674.

12. Laszlo, P. Em The Public Image of Chemistry; Schummer, J.; BensaudeVincent, B.; Van Tiggelen, B., eds.; World Scientific Publishing Co. Pte. Ltd.: Singapore, 2007, cap. 12.

13. Moreau, N. J.; Chemistry International 2005, 27, 6.

14. Castelfranchi, Y. Resumos do II Seminário Internacional Empírika Comunicação, Divulgação e Percepção de Ciência e Tecnologia, Campinas, Brasil, 2012.

15. Indicadores de ciência, tecnologia e inovação em São Paulo em 2010; Brentani, R. R.; Cruz, C. H. B.; Suzigan, W.; Furtado, J. E. M. P.; Garcia, R. C., orgs.; Fapesp: São Paulo, 2011, cap. 12.

16. Amorim, L. H.; Massarani, L. M.; RBECT 2008, 1, 73; Bucchi, M.; Mazzolini, R. G.; PUS 2003, 12, 7; Clark, F.; Illman, D.; Science Comunication 2006, 27, 496; Dutt, B.; Garg, K. C.; PUS 2000, 9, 123; Hijmans, E.; Pleijter, A.; Wester, F.; Science Communication 2003, 25, 153; Massarani, L; Buys, B. Em Los desafíos y la evaluación del periodismo científico en Iberoamérica - Jornadas Iberoaméricanas sobre la Ciencia en los medios masivos; Massarani, L; Polino, C., coord.; AECI, RICYT, CYTED, SciDevNet, OE: Santa Cruz de La Sierra, 2008; Pellechia, M. G.; PUS 1997, 6, 49; da Silva, M. S. T. Marques; Dissertação de Mestrado, Universidade Estadual de Campinas, Brasil, 2011.

17. Bueno, L. O.; Dissertação de Mestrado, Universidade de São Paulo, Brasil, 2010.

18. Augoustinos , M.; Crabb, S.; Shepherd, R.; PUS 2010, 19, 98 
19. Groboljsek, B.; Mali, F.; Science Communication 2012, 34, 30.

20. Castelfranchi, J.; Tese de Doutorado, Universidade Estadual de Campinas, Brasil, 2008.

21. $<$ http://comciencia.br/comciencia/ $/$ section $=8 \&$ edicao $=37 \&$ id $=440>$, acessada em Junho 2013.

22. <http://www.anj.org.br/a-industria-jornalistica/jornais-no-brasil/maioresjornais-do-brasil>, acessada em Maio 2013.

23. Pinto, A. C.; Zucco, C.; Galembeck, F.; de Andrade, J. B.; Vieira, P. C.; Quim. Nova 2012, 35, 2092.

24. Ferreira, V. F.; Quim. Nova 2007, 30, 255.

25. dos Santos, W. L. P.; Rev. Bras. Educ. 2007, 12, 474.

26. Amorim, L. H.; Massarani, L. M.; RBECT 2008, 1, 73; Bucchi, M.; Mazzolini, R. G.; PUS 2003, 12, 7; Massarani, L; Buys, B. Em Los desafíos y la evaluación del periodismo científico en Iberoamérica Jornadas Iberoaméricanas sobre la Ciencia en los medios masivos; Massarani, L; Polino, C., coordenadores; AECI, RICYT, CYTED, SciDevNet, OE: Santa Cruz de La Sierra, 2008.

27. <http://www.estadao.com.br/noticias/impresso,relacao-entre-quimicose-cancer-e-subestimada,552078,0.htm>, acessada em Junho 2013.

28. Chauí, M. Convite à filosofia, Ática: São Paulo, 2000.

29. Adam, D.; Nature 2001, 411, 408.

30. Brotero, P. P.; Dissertação de Mestrado, Universidade de São Paulo, Brasil, 2006.

31. de Amorim, L. H.; Dissertação de Mestrado, Instituto Oswaldo Cruz, Brasil, 2006.
32. Bentley, P.; Kyvik, S.; PUS 2011, 20, 48.

33. dos Santos, E. R. A.; de Souza, C. M.; Ferraz. M. C. C.; Hayashi, M. C. P. I.; Furnival, A. C. M.; Resumos do II Seminário LECOTEC de Comunicação e Ciência, Bauru, 2009.

34. Editorial; Nature 2001, 411, 399.

35. <http://www.estadao.com.br/noticias/vidae,quimicos-brasileiros-padraointernacional,737705,0.htm>, acessada em Junho 2013.

36. <http://www1.folha.uol.com.br/bbc/973753-droga-com-flor-do-egitoantigo-combate-cancer-em-cobaias.shtml>, acessada em Junho 2013.

37. <http://www.estadao.com.br/noticias/geral,lei-das-cobaias-einexequivel-diz-secretario-do-rj,104492,0.htm>, acessada em Junho 2013.

38. <http://www1.folha.uol.com.br/colunas/helioschwartsman/1065195tabaco-sem-gosto.shtml>, acessada em Junho 2013.

39. Castelfranchi, Y. Em Jornalismo e ciência: uma perspectiva iberoamericana; Massarani. L., coord.; Fiocruz: Rio de Janeiro, 2010.

40. <http://www.quimica2011.org.br/>, acessada em Junho 2013.

41. Marson, G. A.; Galembeck, E.; de Andrade, J. B.; Quim. Nova 2013, 36, 484.

42. <http://www.amazonia.fiocruz.br/br/noticias/41-destaques/996jornalista-e-pesquisadores-debatem-temas-na-area-de-quimica-comopauta-para-a-midia.html>, acessada em Junho 2013. 